This article was downloaded by: [National Taiwan University]

On: 30 October 2009

Access details: Access Details: [subscription number 769798964]

Publisher Taylor \& Francis

Informa Ltd Registered in England and Wales Registered Number: 1072954 Registered office: Mortimer House, 37-41 Mortimer Street, London W1T 3JH, UK

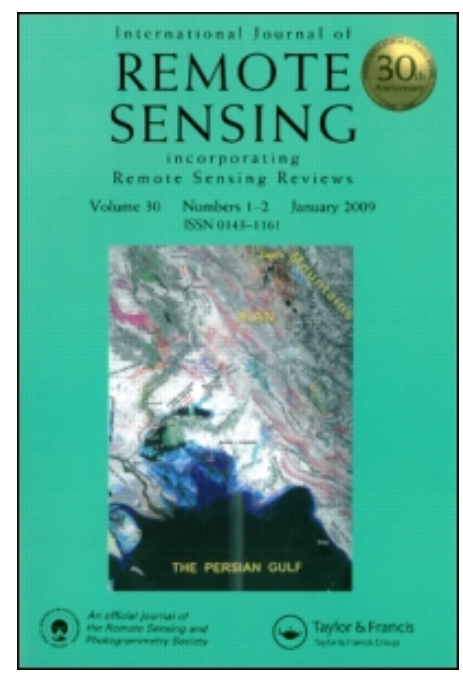

International Journal of Remote Sensing

Publication details, including instructions for authors and subscription information:

http://www.informaworld.com/smpp/title content=t713722504

\title{
Side-scan sonographs of steep slopes in the Wushieh Reservoir
}

G.-S. Song a

a Institute of Oceanography, National Taiwan University, Taipei 106, Taiwan—Republic of China

Online Publication Date: 01 January 2007

To cite this Article Song, G.-S.(2007)'Side-scan sonographs of steep slopes in the Wushieh Reservoir',International Journal of Remote Sensing, $28: 8,1857-1871$

To link to this Article: DOI: $10.1080 / 01431160600935612$

URL: http://dx.doi.org/10.1080/01431160600935612

\section{PLEASE SCROLL DOWN FOR ARTICLE}

Full terms and conditions of use: http://www.informaworld.com/terms-and-conditions-of-access.pdf

This article may be used for research, teaching and private study purposes. Any substantial or systematic reproduction, re-distribution, re-selling, loan or sub-licensing, systematic supply or distribution in any form to anyone is expressly forbidden.

The publisher does not give any warranty express or implied or make any representation that the contents will be complete or accurate or up to date. The accuracy of any instructions, formulae and drug doses should be independently verified with primary sources. The publisher shall not be liable for any loss, actions, claims, proceedings, demand or costs or damages whatsoever or howsoever caused arising directly or indirectly in connection with or arising out of the use of this material. 


\title{
Side-scan sonographs of steep slopes in the Wushieh Reservoir
}

\author{
G.-S. SONG* \\ Institute of Oceanography, National Taiwan University, PO Box 23-13, Taipei 106, \\ Taiwan-Republic of China
}

(Received 15 December 2005; in final form 24 February 2006)

\begin{abstract}
Operators tow side-scan sonar transducers at the optimum height from the bottom to produce better quality side-scan sonographs. This can be done only if the bottom is moderately flat. Sonographs with maximum tonal intensity are easily produced on steep slopes e.g. valley banks. Strong signatures are recorded over all ranges due to the poor geometry of sonographs produced without acoustic shadows. In order to create clear scanned images of a steep slope using a side-scan sonar, rotation of the towed fish or tilting the transducer face to the dipping slope surface is suggested. Cases conducted on the shore of the Wushieh Reservoir, Taiwan, in which the bank slopes varied from $10^{\circ}$ to $45^{\circ}$ are discussed in this work. In general, the angle of the scanned slope determines the degree of towed fish rotation angle. The rotation angle is set at a smaller angle than the slope, giving stronger returns from the lower slope. In contrast, if the rotation angle is set at a larger angle a null return outside the insonified area in the lower slope is produced. A sub-aqueous landslide was observed in the side-scan sonographs using this strategy. This study also gives results that affirm the value of a side-scan sonar as a powerful tool for underwater inspection.
\end{abstract}

\section{Introduction}

Side-scan sonar survey is used worldwide. It is used in the ocean by hydrographers, marine geologists, and has been extended to the field of environmental applications. One of these applications is the investigation of hydrological land use in lakes and reservoirs where lots of siltation has occurred or where there is an abundance of deposits carried into territories from upstream or by landslides from slopes (McManus and Duck 1983, Duck et al. 1993).

The side-scan sonar is routinely used. Sometimes it is used by relatively inexperienced personnel, making the scanned image quality too poor to interpret. This is because the key to success is in understanding the geometry of the acoustic wave propagation to the insonified targets. The production of substantial shadows in the record for objects that protrude above the bottom is critical.

A good sonar record is one that shows great detail. Bottom echo returns from a strong reflector will be printed as dark lines or areas. An acoustic shadow behind a protruding object produces a light area on the record. This means that a good record is one with approximately even intensity over the entire data range. The recorder gain settings must be tuned to create proper acoustic shadows.

To create shadows, operators are always trying to tow the side-scan sonar transducer at an optimum height above the bottom in the field. Generally, the rule is

*Email: songs@ntu.edu.tw 
to set the height at $10-25 \%$ of the selected scan range (Flemming 1976, Fish and Carr 1990). However, sonographs with maximum tonal intensity are easily produced on the steep slopes on valley sides. The steep slopes are usually indicative of the lack of bedrock in the sediment veneer. However strong signatures are recorded over this range mainly because poor geometry produces sonographs without acoustic shadows.

Reservoirs are usually located among upstream territories in mountain areas. In Taiwan, civil engineering safety checks of the facilities are regularly conducted, mainly under the influence of earthquake activity within seismically active valleys. These earthquakes can trigger underwater mass movements in reservoirs; even when no evidence of spectacular landslides is found on the surface slopes.

The 921 Chi-Chi Earthquake occurred in 1999 in the Taichung area of Taiwan. In the following years the Wushieh Reservoir area lost about $10 \%$ of its storage capacity (about 10 million tons), replaced by sediments (Song 2002). Although most of the deposits accumulated inside the reservoir were carried from upstream during the rainy season rather than from this catastrophic event (Song 2004), the possibility that the debris built up along the foot of steep slopes was produced by sub-aqueous landslides cannot be discounted.

In this study, the sub-aqueous landslide speculation was investigated and interpreted from the side-scan sonographs. The incident angle of the acoustic beam from the side-scan transducer was adjusted accordingly, to create and to give a good sonar record upon the reservoir slopes. As illustrated, this study served to affirm the value of a side-scan sonar as a powerful tool for underwater inspection. Most importantly, this study suggests an alternative deployment of the side-scan transducer sonar to give the best quality sonar image on the very steep slopes.

\section{Side-scan geometry and transducer deployment}

A side-scan sonar system used in the experiment includes the Oceanstar ST-8000 sonar transceiver, Edgetech 272TD towed fish, and the Seasone Hunter acquisition system. The towed fish contains two transducers, with separate port and starboard components located on each side of the body. It is towed instead of hull-mounted, simply because the transducer can be placed near the water bottom which is desirable for quality sonar data.

The sonar beams formed by the 272TD towed fish are shaped especially for generating the highest resolution possible. In the field, we were using its specified lower frequency at $100 \mathrm{kHz}$, and produces a main sonar beam $1.2^{\circ} \times 50^{\circ}$ at half power point $(-3 \mathrm{~dB})($ EdgeTech 1988$)$, or about $2.0^{\circ} \times 100^{\circ}$ at one eighth power point $(-9 \mathrm{~dB})$ (Fish and Carr 1990). In addition, the beam axes are also directed $20^{\circ}$ below the horizontal (figure 1).

As shown in figure 1, the acoustic pressure peak of the main vertical lobe is about $20^{\circ}$ below the horizontal. The sonar sensitivity should be sharply reduced above the water surface, as well as reduced uniformly to the minimum vertical downwards at so-called nadir. For GLORIA long range side-scan sonar, the beam pattern shows the small null of signal about $20^{\circ}$ off nadir (Searle et al. 1990). In the null, the loss of signal is significant, but several side lobes can be seen there. In fact, the minimum always occurred in a null between the main lobe and first sidelobe (Searle et al. 1990).

While the main beam is tilted $20^{\circ}$ below the horizontal, the signal maximum should be at 2.75 times the depth of the towed fish without considering the 


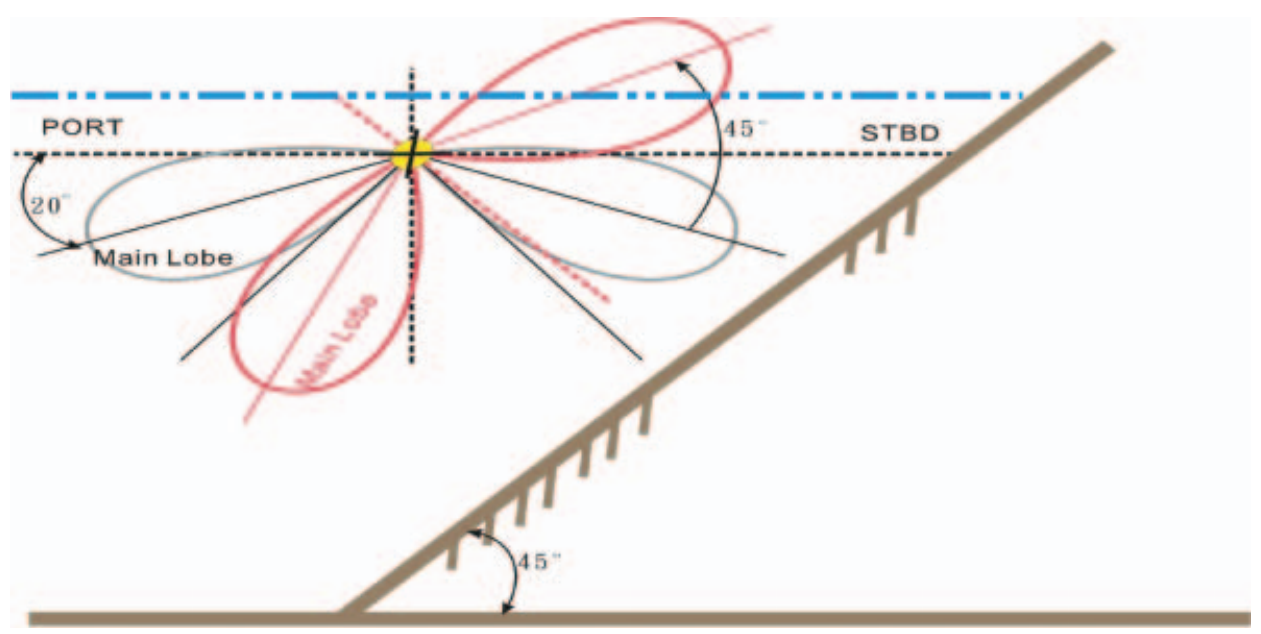

Figure 1. Power directivity diagram of the vertical sonar beams transmitted from towed fish. The yellow solid circle represents the location of the towed fish. The main beam lobes are denoted by grey lines. The side lobes are not shown for clarity. The blue dashed line denotes the water surface. The body of the towed fish can be tilted $45^{\circ}$ counterclockwise such that the beam directivity (red main lobes) related to the bottom (bold black lines) can be changed as shown.

refraction factor. However, Searle et al.'s (1990) calculation indicated that the maximum occurs closer to the towed fish (about twice the distance of the towed fish depth), and the energy falls off more rapidly with increasing range, especially in shallower water.

Longer ranges can give greater bottom coverage, but shorter ranges can provide a higher resolution for object recognizability. In addition, the quality of the sonar image is determined by the height of the towed fish above the bottom. For the transducers tilted down to $20^{\circ}$, the towed fish has been suggested to be positioned at a depth of about $20 \%$ of the sonar range setting (Fish and Carr 1990). As a result, the signal maximum occurs in the middle of the selected range shown in the designated record. If the towed fish is too high off the bottom, shadowing will be lessened and target recognition may be harder. If it is too low the signal energy is reduced without echo returns at the outer ranges.

At $20 \%$ of the range, setting is based on the distance between the flat bottom and the towed fish. However, a towed fish may be towed at a higher altitude than recommended when the bottom exhibits greatly fluctuating bathymetry. In this case, target resolution on the bottom is traded off. This ill condition is exposed especially when a high angle slope is scanned. In areas such as in a reservoir, the shore around the water is usually presented as a valley slope to a submerged fault scarp. Examination of sonograph texture or target shown on the steep slope shows that resolution is poor either by too strong coherent returns or by null signal under specified beam directivity.

Figure 2 shows the side-scan image of the shore of the Wushieh Reservoir. The gradient of the section is at about $20^{\circ}$; however, different looks of the image are shown to either side of the channels. The acoustic lobe of the starboard component pointed downslope gave acoustic shadows on a large portion of the record; especially at places where the towed fish was towed at $20 \%$ ratio as recommended. In 


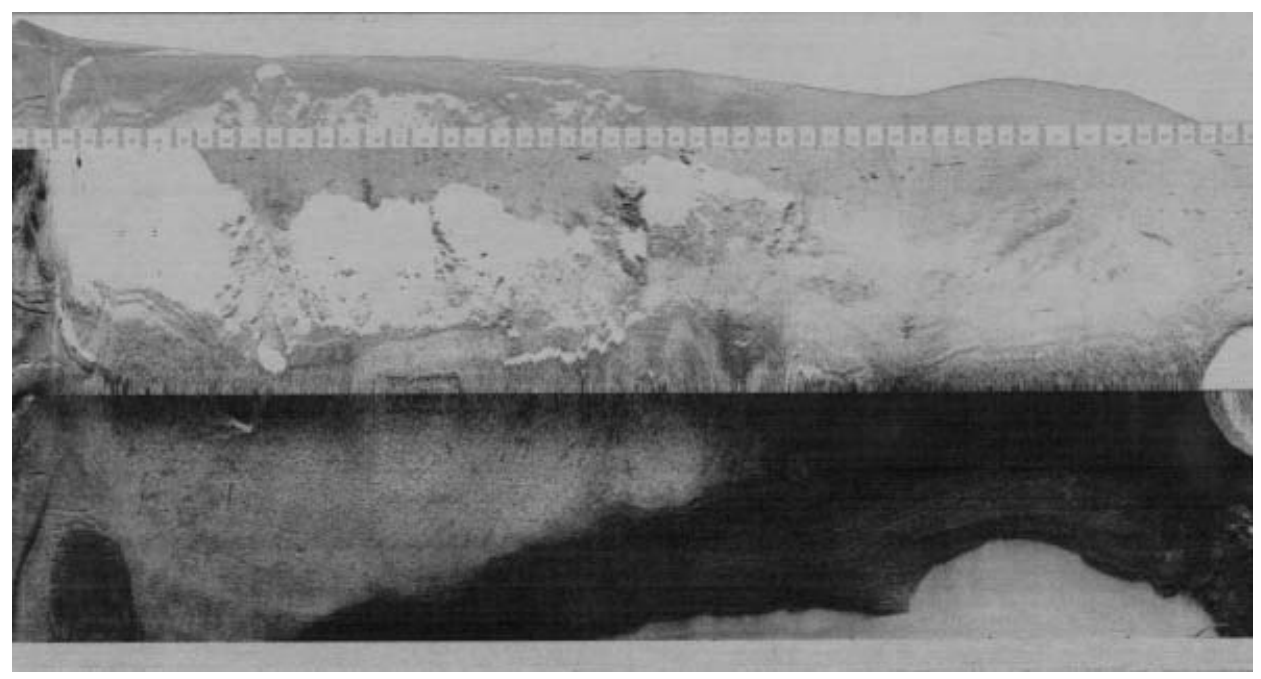

Figure 2. Side-scan image showing the slope area of the Wushieh Reservoir, Taiwan. There are three recorded portions displayed. The narrower upper portion is the third data channel showing mainly the towed fish altitude. The range scanned in this record is $50 \mathrm{~m}$, so the total range from both channels (starboard channel on the top and port channel on the bottom) is $100 \mathrm{~m}$. The images on both channels are shown in the slant range corrected mode. This removes the water column bringing the two first bottom returns together. Light area on the record indicates almost no acoustic energy returned.

contrast, the acoustic lobe of the port component pointed upslope gave very strong energy returns, especially at areas where the towed fish was towed higher than recommended.

To create a clear scanned image on a steep slope using a side-scan sonar, rotating the towed fish or tilting the transducers to the dipping surface of the slope is suggested. Under these circumstances, only one channel is usable. This is because the main lobe of the other channel is easily pointed above the horizontal (figure 1), creating water surface reverberations or multipath images.

In general, the dipping angle of the scanned slope determines the degree of rotated angle of the towed fish as shown in figure 1. Figure 3 demonstrates the nadir located on the slopes while the towed fish is rotated $45^{\circ}$ in the upslope direction. The calculations were based on a known water column depth $(D)$, the slope dipping angle $(\theta)$, and the surveyed distance of first bottom return $(L)$. As a result, the quality of sonar image on the slope may be controlled using the distance $L$ related to the slope coverage. The best range setting was at 5 times $L$, which may cover all the way to the bottom of the slope.

Following figure 3, the depth of the towed fish to the bottom of the slope $(D)$ is $37 \mathrm{~m}$. The towed fish is rotated for a $45^{\circ}$ slope accordingly. In this case, the port component is the only channel in view, and its scanned range $\left(X_{D}\right)$ is at 52.3-L. Then we design a survey route deploying the towed fish towed parallel to the shore line at a separation distance $S$ (or at $1.414 L$ ), such that it is satisfied with setting the distance of first bottom return $(L)$ at $20 \%$ of the range $X_{D}$. Under the condition, the best combination of getting an optimal record is as follows; selected scanned range at $50 \mathrm{~m}$ and towed fish surveying at about $12 \mathrm{~m}$ from the shore line. 


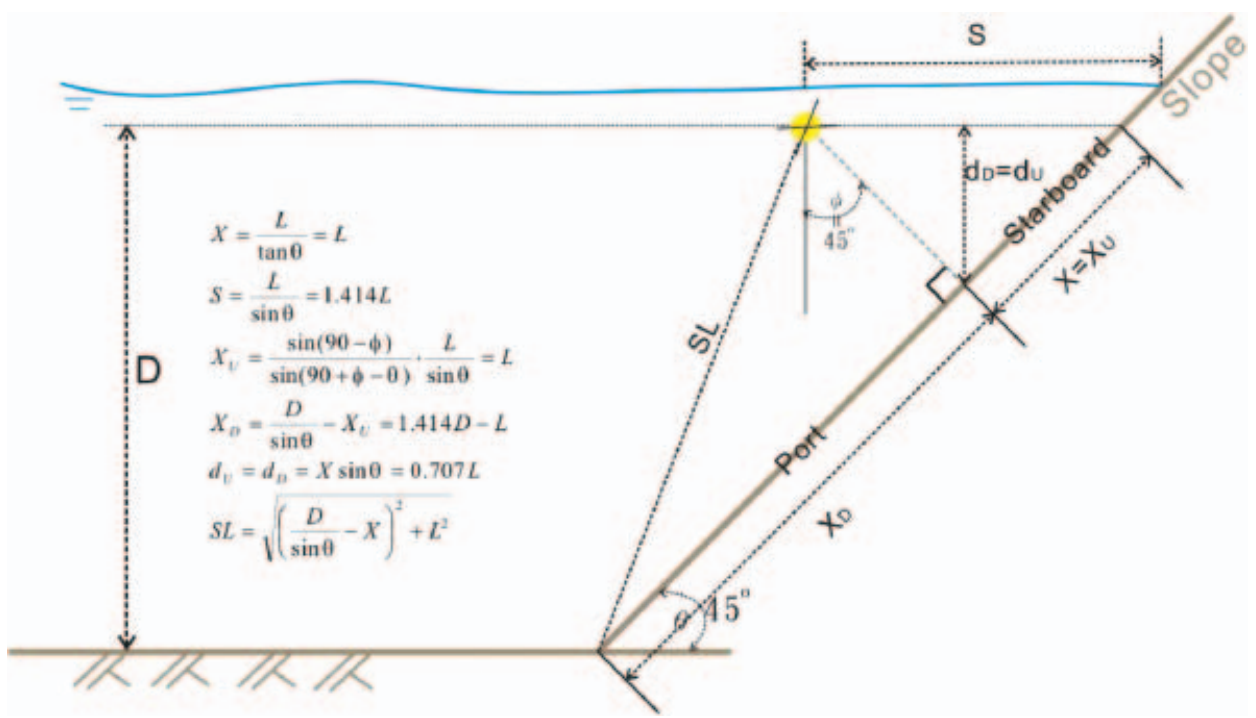

Figure 3. Geometry of scanned image by a $45^{\circ}(\phi)$ rotated side-scan towed fish. The slope dips at $45^{\circ}(\theta)$. There is a variant depth of water $(D)$ from $25 \mathrm{~m}$ to $50 \mathrm{~m}$ in the Wushieh Reservoir, Taiwan.

The above case presents about $9 \mathrm{~m}$ of the upper slope displayed in the starboard channel. This view is poorer in resolution due to the multipath effect. We can make the nadir increase by deploying the towed fish closer to the shore line. For instance, the fish height may be towed at a minimum of $10 \%$ of the range setting without totally losing acoustic returns in the outer range of the record (Fish and Carr 1990). Hence, the slope can be scanned and displayed in the port channel further upslope for another $4-5 \mathrm{~m}$ with a surveying track about $7 \mathrm{~m}$ away from the shore line. However, there is a greater chance of weak acoustic returns that may come from the lower section of the slope.

If the scanned image can include and identify targets lying on the flat area next to the bottom of the slope, the possibility of the accumulation of debris built up next to the foot of the slope can be investigated. For that purpose, the scanned range can be set at $75 \mathrm{~m}$ in the case shown in figure 3 , and the ratio is at $12 \%$, which is still acceptable for quality. However, the image may become poor in the area beyond the slope if the towed fish is rotated at respectively large angles. An alternative to inspecting the targets next to the slope is to rotate the towed fish less than the downwards angle of the slope.

\section{Survey results in the Wushieh Reservoir}

The Wushieh Reservoir was investigated by the side-scan sonar in 2004. One goal of the project was to see if there was any possibility of the occurrence of subaqueous landslide and the accumulation of debris built up along the foot of steep slopes. The towed fish was placed into the water using a rope by the side of a survey raft; it could be rotated to any desired angle using a designed steel frame. During the survey, a C/A coded GPS was used to navigate the towed fish following a preset route. 


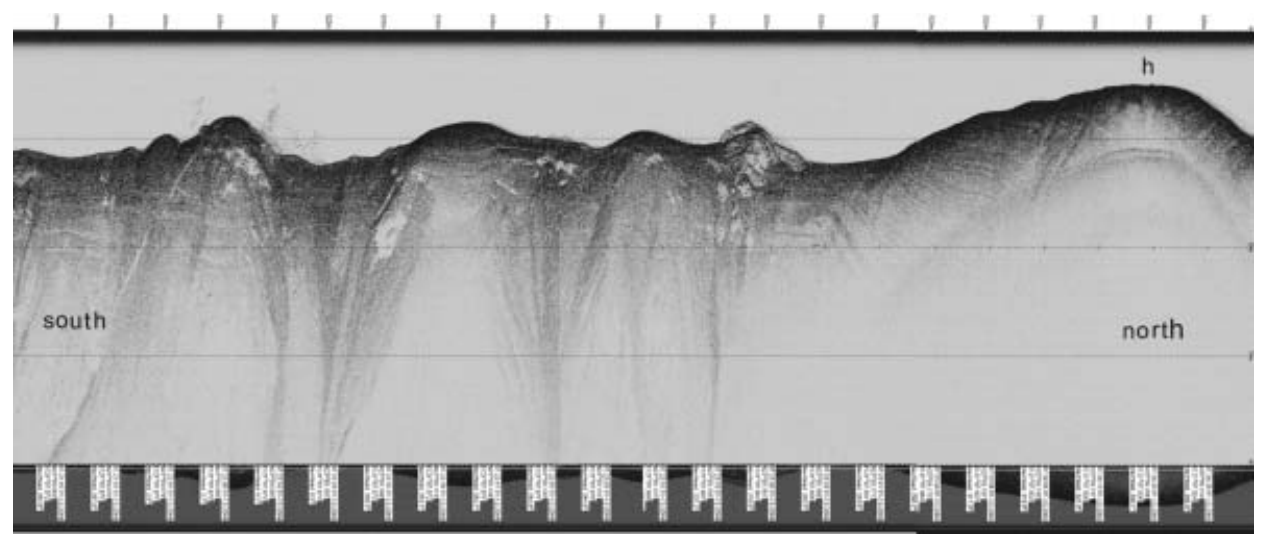

Figure 4. Port channel of the side-scan image to one western bank section of the Wushieh Reservoir, Taiwan. The scanned range is at $50 \mathrm{~m}$, so the slant interval between each pair of scale lines is $12.5 \mathrm{~m}$.

The first attempt was to rotate the towed fish as shown in figure 1 or figure 3. Starting from the first bottom return, we can see a very clear image of the slope of the reservoir on the record. The slope roughness as well as the slope meandering are shown in figure 4. However, the slope image cannot be displayed throughout the whole record on the port channel. This is because the downward angle of the slope in this section is too gentle compared with the $45^{\circ}$ rotation of the towed fish.

Figure 5 shows the geometry of a $30^{\circ}$ slope scanned by a $45^{\circ}$ rotated towed fish. Some problems were created in terms of the target image that is displayed on the record, compared with that demonstrated in figure 3 of a $45^{\circ}$ slope;

(1) the nadir is not in the nearest point to the towed fish,

(2) there is an overlap zone from acoustic returns at a distance of $P$,

(3) the point of the maximum of the signal migrates upslope,

(4) a deeper $L$ or a longer slant range setting $\left(S L\right.$ or $X_{D}$ ) to totally cover the targets on the slope is required.

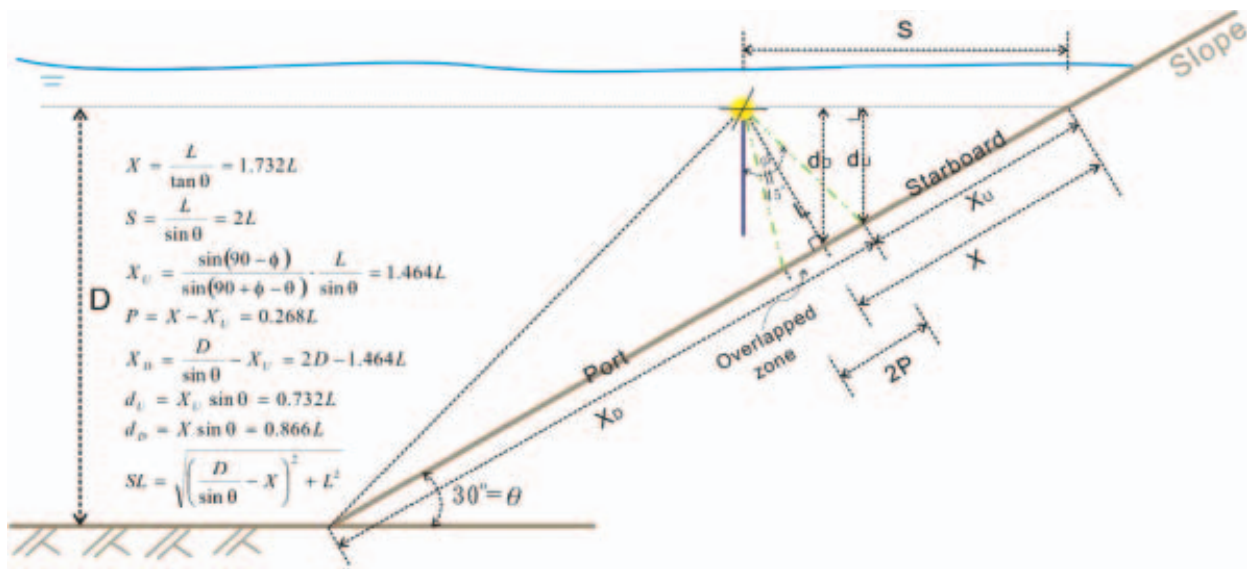

Figure 5. Geometry of the scanned image by a $45^{\circ}(\phi)$ rotated side-scan towed fish. The slope dips at $30^{\circ}(\theta)$. 


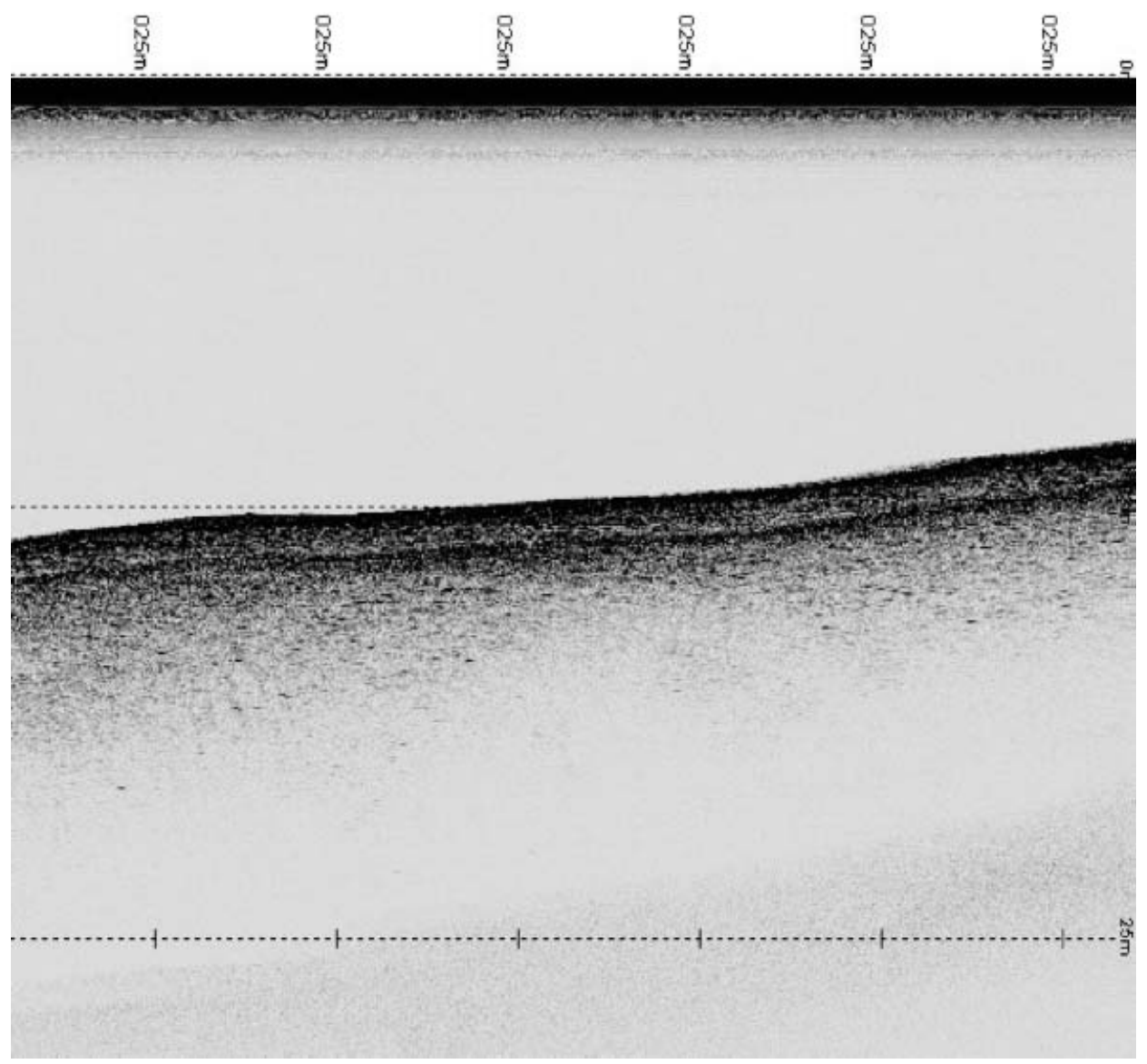

Figure 6. Side-scan image showing the overlapped zone in the area of the first bottom returns.

As a result, the image resolution could be poorer under the situation. The signal will be mixed with noises in the acoustic overlapped zone following the water column return (figure 6), and the signal strength will decay faster in the lower section of the slope if the slope is gentler. However, other than those, a proper increase in the tilted angle of the towed fish related to the dip of the slope, may provide an improved look to the upper section of the slope image.

Figure 7 demonstrates the insonified spatial relationship of a rotated towed fish sonar beam to the slope in the designed angles. It is assumed that the insonified area of the slope is merely covered by a half power point sonar beam. As a result, the lower portion of the slope will be outside of the insonified area with very weak acoustic return for slope angles less than $28.7^{\circ}$ when the towed fish is rotated $45^{\circ}$, or less than $13.7^{\circ}$ if the towed fish is rotated by $30^{\circ}$. Under these conditions, the distance of the first bottom return $(L)$ is located at $20 \%$ of the slant range setting. As shown in figure 4 , the ' $h$ ' section poses a narrow insonified region, followed by an acoustic multiple return (a second bounce reflected from the water surface). The dip of the slope in this section is around $12^{\circ}$ (Song 2004), giving an insonified distance at $1.85 \mathrm{~L}$ according to figure 7 , which matches with the image shown in the record. To 


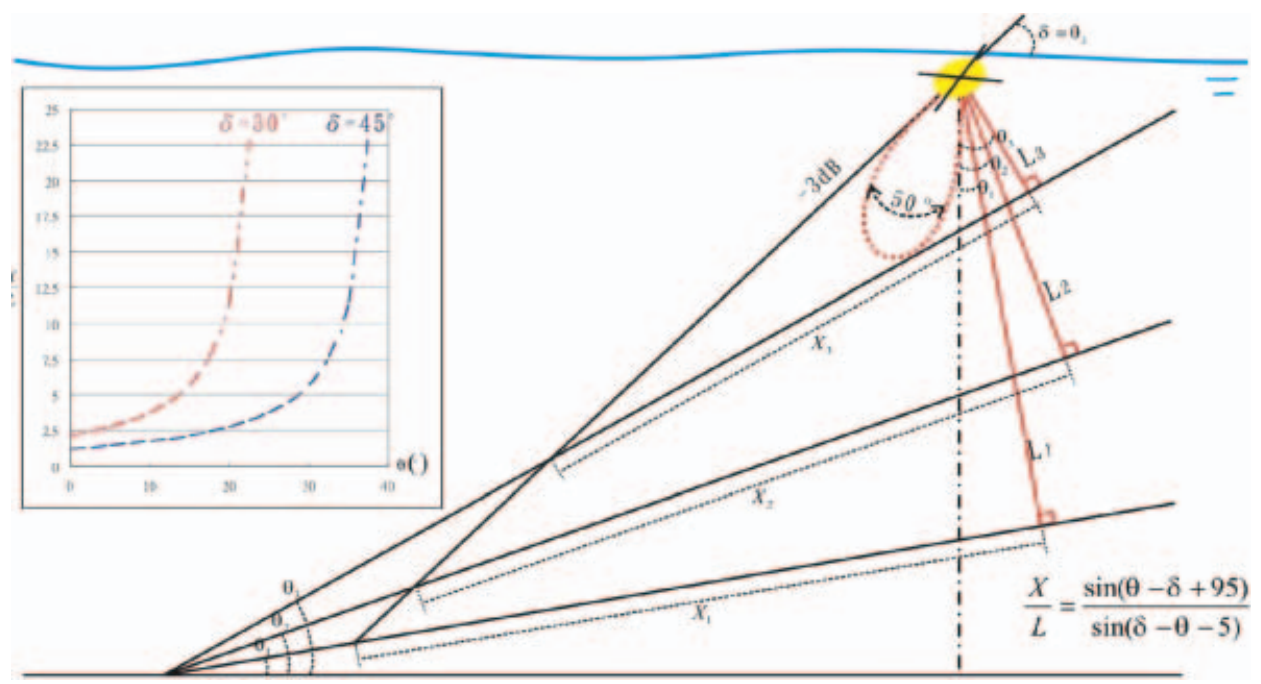

Figure 7. Coverage of the side-scan sonar beam at half power point $(-3 \mathrm{~dB})$ on the slope at an angle of $\theta$. Geometry is illustrated when the towed fish is rotated by $\theta 3$. Three different slopes, $\theta 1, \theta 2, \theta 3$ give different beam insonification coverage at $X 1, X 2$, and $X 3$, respectively. The inset on the left shows the relationship between the $X / L$ ratio at $-3 \mathrm{~dB}$ beam width versus slope angles, with the towed fish rotated by $30^{\circ}$ and $45^{\circ}(\delta)$, respectively. $L$ stands for the distance of the first bottom return shown on the record.

the south of the section shown in figure 4 , the dip of the slope becomes $20^{\circ}$, such that the insonified image on the slope extends wider in the record.

Figure 8 gives the side-scan images showing the stair incised on the slope. The one on the left, rotated angle of towed fish was adjusted based on the slope angle. It then displays a stronger energy returns from the slope than the others. However, the image of upper end of the slope became poorest due to the nadir insonification. In
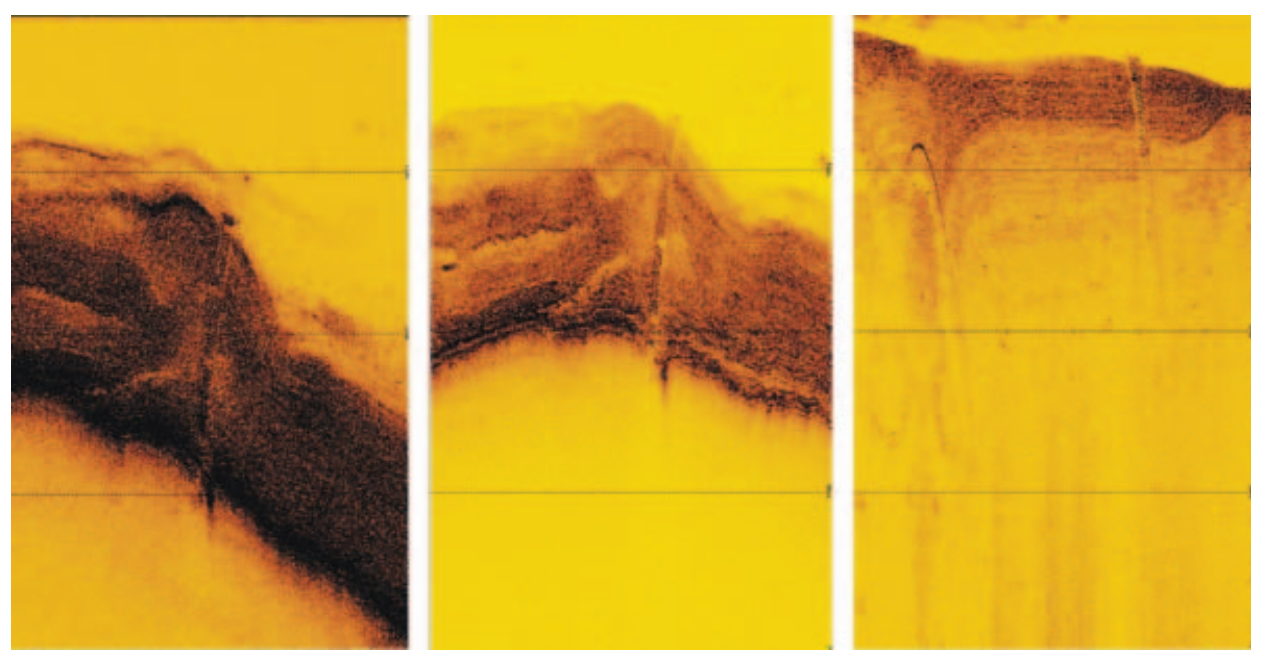

Figure 8. Stair images located downslope of the water bank of the Wushieh Reservoir, Taiwan. From left to right, the towed fish was rotated further upwards related to the bank. The slant range of the images is at $75 \mathrm{~m}$. 


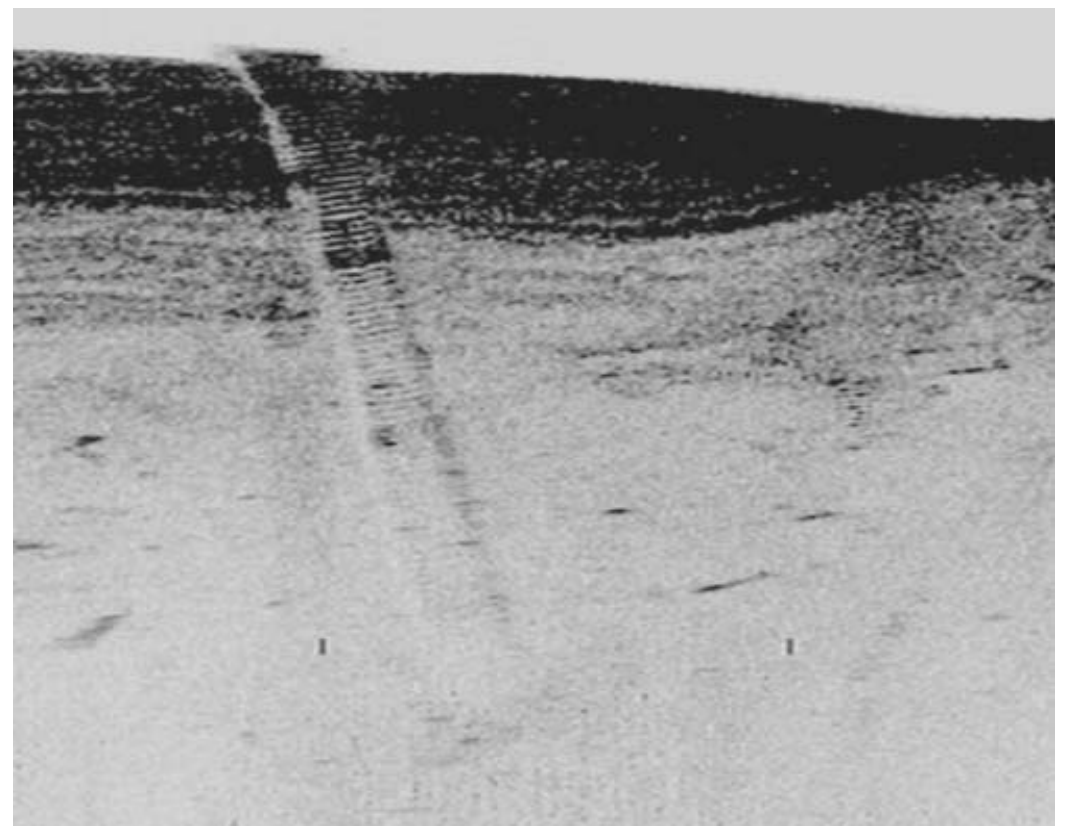

Figure 9. Enlarged image of the stairs to the bank of the Wushieh Reservoir, Taiwan, using a towed fish rotated $30^{\circ}$. The lower portions of the slope, having always been submerged, show no strand line incised by water energy.

the middle of figure 8 , the towed fish was rotated at a slightly larger angle than the desired angle in respect to the slope, giving a nice quality image through the entire stair to the bottom of the reservoir. On the right, using a greater towed fish angle produced an image similar in quality to figure 4 . Figure 9 shows the enlarged image to the slope in the vicinity of the stairs using the towed fish rotated at an angle similar to the right of figure 8 . In this image, we can clearly identify strand lines shown on the bank. Furthermore, it also exposes the variant upslope gradient following the stairway trend.

Figure 10 shows the details of the scanned image with the towed fish rotated $45^{\circ}$ facing the intake structure into the water at a downwards gradient of about $45^{\circ}$. Although at the front of the towed fish intake was distant at $60 \%$ of the range setting from the first bottom return, it provided the exact shape of the structure. However, partially without a slant range correction to the image, we can still observe the structures' appearance with a little distortion, with the intake image in the upper racks being compressed and curved. Furthermore, when we compare the images in its vicinity with those images conducted by rotating the towed fish $30^{\circ}$ (figure 11), it looks like those images were taken by observing the bank with two variant inclinations. Lower inclination (more downwards) gave the same effect as from a $30^{\circ}$ rotated towed fish. When facing a $30-40^{\circ}$ slope, a clear foothill image stood by the steep slopes was shown. Obstacles in front of the bottom racks of the water intake were observed.

After the 921 Chi-Chi Earthquake, the bank of the Wushieh Reservoir suffered a landslide (figure 12), such that the possibility of debris accumulation along the steep under-water slopes could not be precluded. By rotating the towed fish to view the foothill territory of the reservoir under water, the location of the landslide denoted 


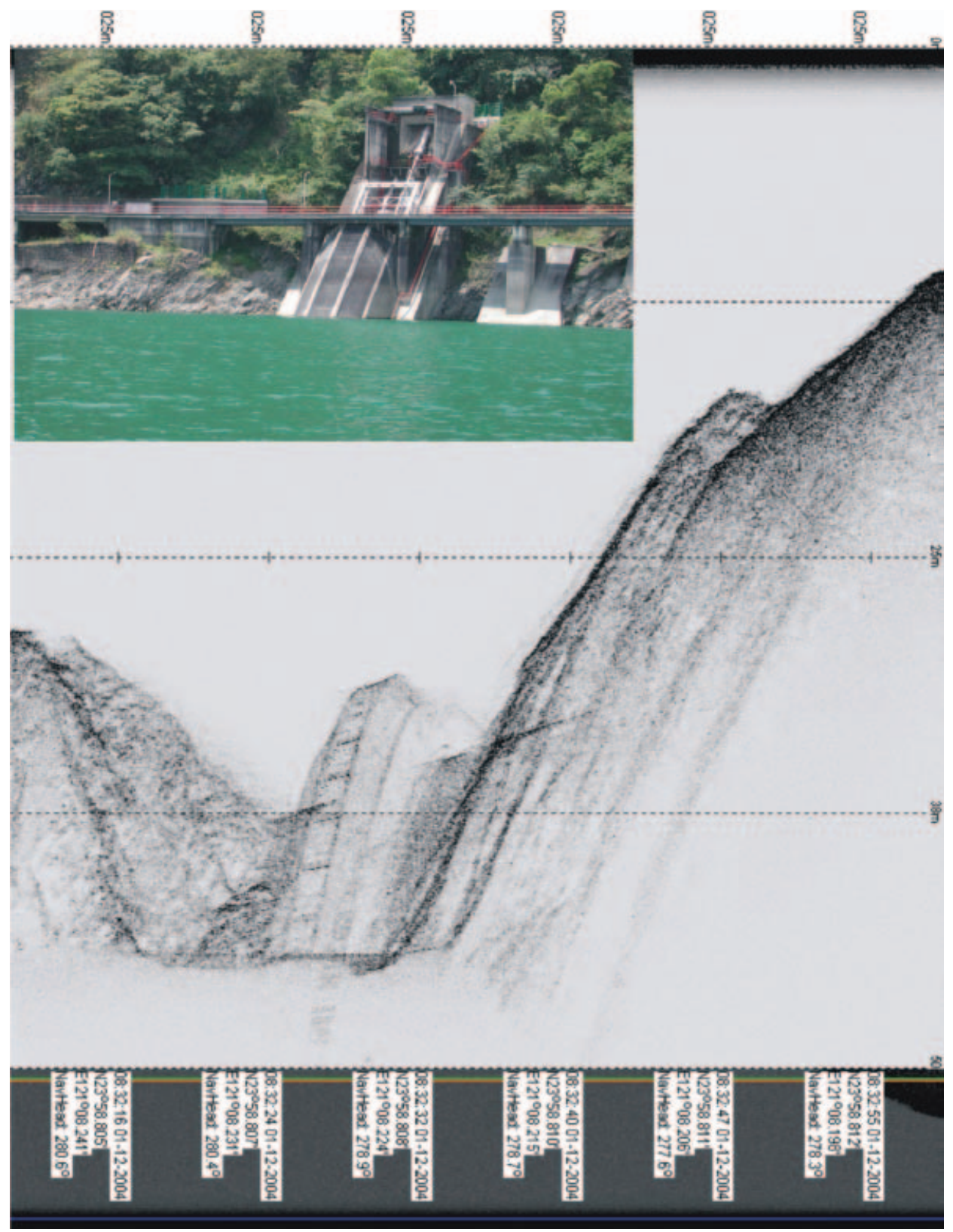

Figure 10. Side-scan image showing the electric power plant water intake in the Wushieh Reservoir, Taiwan, in the water column. A look above the surface refers to the picture on the corner. The slant range of this port channel was set at $50 \mathrm{~m}$.

in figure 12 showed that almost no debris is accumulated beneath the water surface (figure 13). Even more, those steep slopes surrounding the water of the Wushieh Reservoir were checked accordingly (Song 2004). The wall beneath the strand line of the slope has been submerged in the water since the power plant was built. Except for one place this investigation indicated that the slope had been firm without sub-aqueous slumping, as shown in figure 14. 

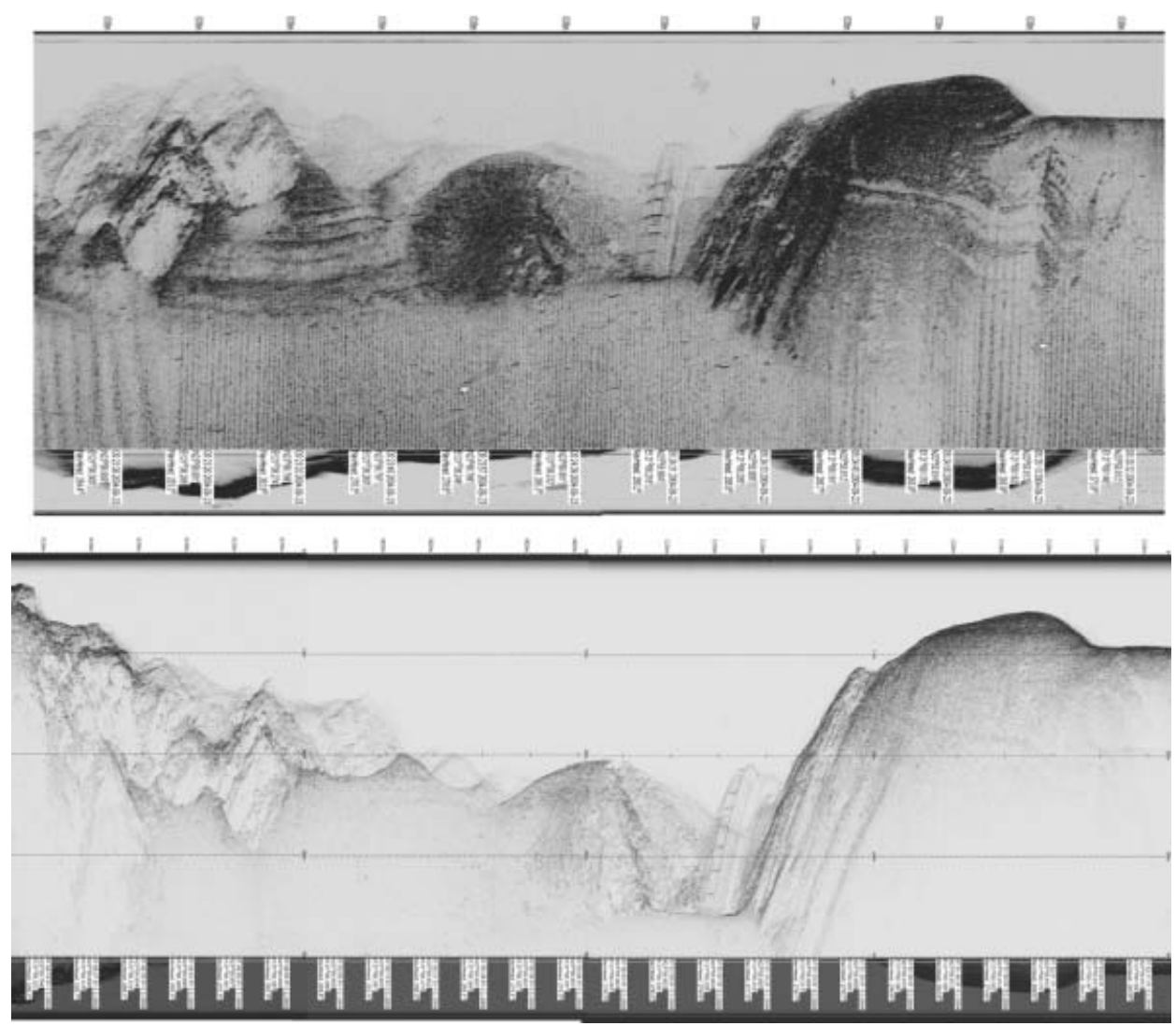

Figure 11. Side-scan images to the slopes of the intake area. (a) Image produced by rotating the towed fish $30^{\circ}$ with a slant range at $75 \mathrm{~m}$. A clear strand line shown on the slope indicates the elevation at $979 \mathrm{~m}$ (Song 2004). Down across the foot of the slope, the flat bottom is at $960 \mathrm{~m}$. (b) Image produced by rotating the towed fish $45^{\circ}$ with a slant range set at $50 \mathrm{~m}$, giving a null signal return to the bottom portion of the slope.

Figure 15 shows the sole slump location found across the strand line of the slope. Observing the underwater topography measured by the multi-beam echo-sounder, the location around the edge of the deposit fan in the reservoir is indicated (Song 2004). The sediments once crossing the edge creep down following the slope of the fan, as shown in the 3-dimensional diagram. However, in figure 15, the side-scan image presented evidence that some deposits were carried into the reservoir by landslides from the slopes in this location. In position 2, the bank was covered by slump debris. Debris was transported outwards from the foothill side of the bank, with coarser grains left behind in position 3. On the slope where the wall was not covered by the slump material there is a steeper gradient at the foot of the slope, delivering an acoustic shadow in the region (the white band in between the slope and the flat bottom).

Using a towed fish rotation, side-scan images can display some details even to the flat bottom next to the steep slope beneath the water mass. Figure 16 shows many linear acoustic signals spreading over the bottom area. The evidence taken from the video by a towed underwater camera in that area indicated that they were fragments 


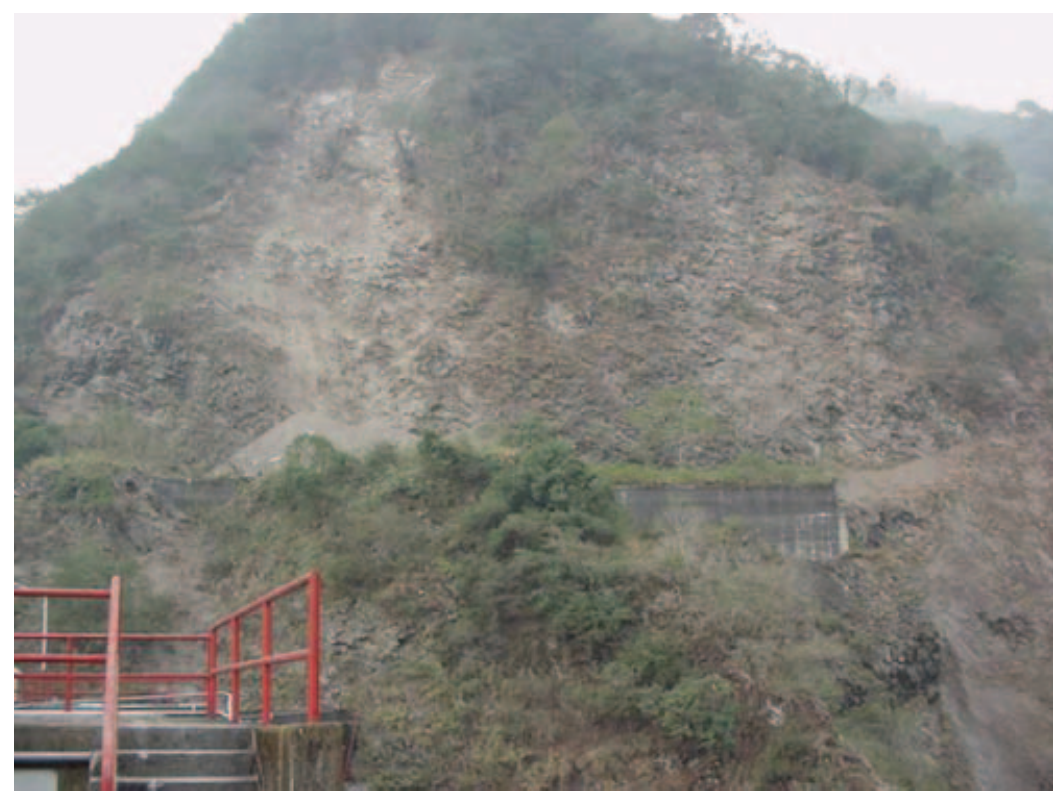

Figure 12. Picture showing the local slumping occurring on the wall off the slope in the Wushieh Reservoir, Taiwan, from the 921 Chi-Chi Earthquakes.

of wood carried by river flow from the catchments during the flood caused by stormy weather (Song 2004). Debris was found dropping into the deep with the silt resting at the bottom (figure 17). Figure 16 indicates that debris was abundant all over the places where the suspension load was dominant (Song 2002, 2004).

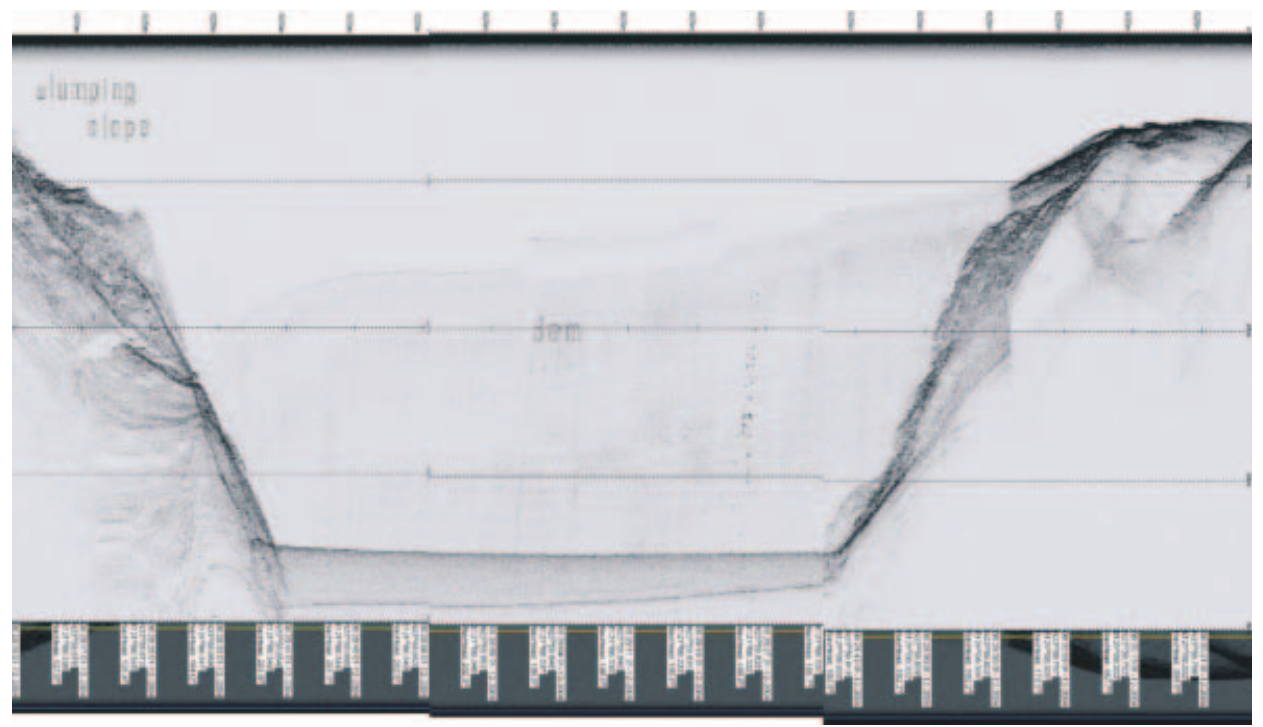

Figure 13. Side-scan image view of the slope foot at the slumping area. The location was close to the end of the Wushieh Reservoir dam, Taiwan. It is on the left hand side of the figure. It is clear that the bottom of the slope is clean without any accumulation debris. 

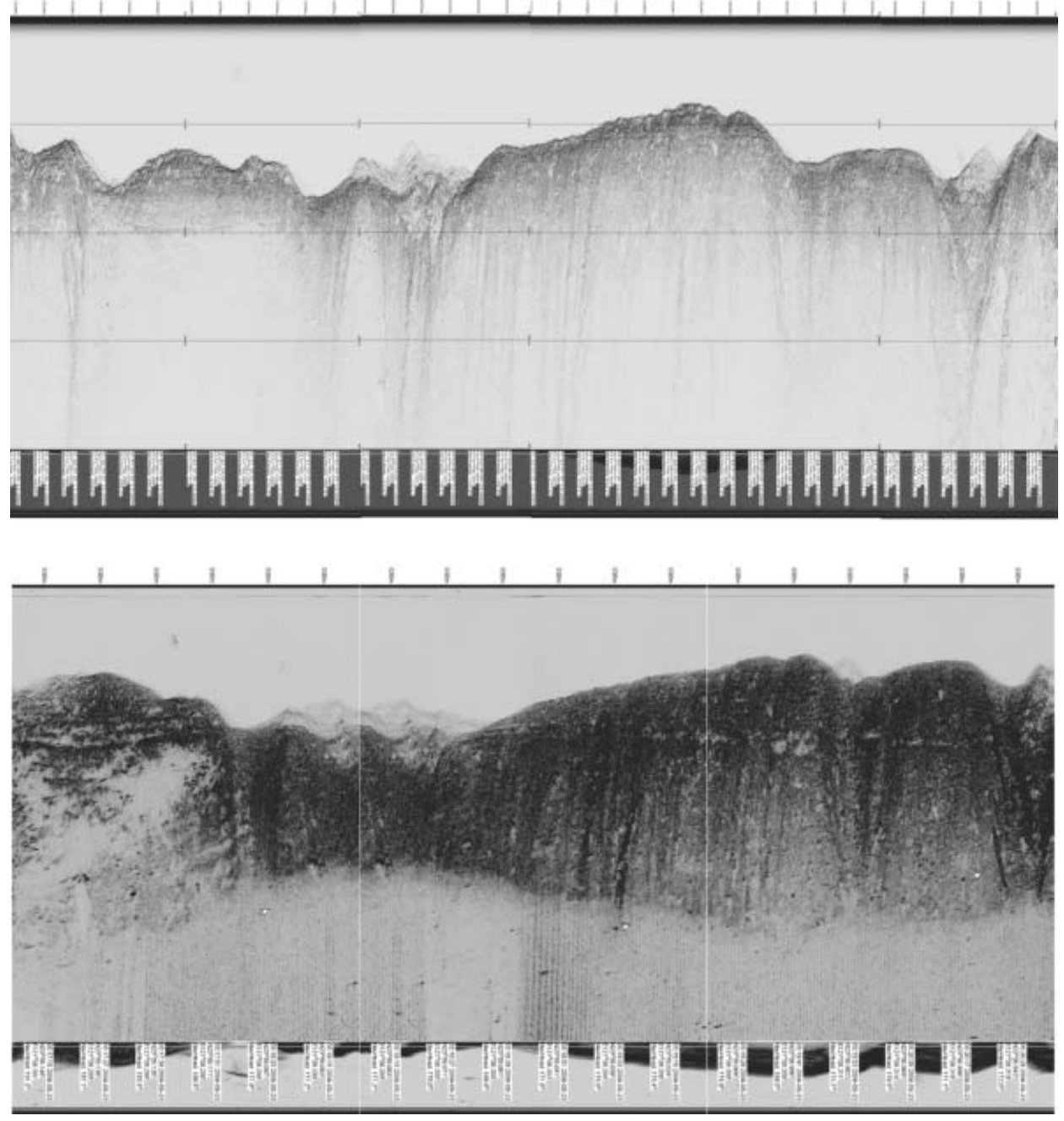

Figure 14. Side-scan images to the $30^{\circ}$ slopes of the reservoir. (a) Image produced by rotating the towed fish $45^{\circ}$ with a slant range at $50 \mathrm{~m}$. (b) Image produced by rotating the towed fish $30^{\circ}$ with a slant range setting at $75 \mathrm{~m}$.

\section{Conclusion}

In this study, a sub-aqueous landslide was observed using side-scan sonographs of the Wushieh Reservoir, Central Taiwan. The incident angle of the acoustic beam from the side-scan transducer was adjusted in relation to the downwards angle of the slope. The images provided information on underwater mass movement that no other instruments can support. This study has produced results affirming the value of the side-scan sonar as a powerful tool for underwater inspection of civil structures constructed on a steep slope.

\section{Acknowledgments}

The author would like to thank C.J. Lin, Director of the Wanda Hydroelectric Power Plant, Taiwan, and Engineer D.C. Young of the Taiwan Power Company for 

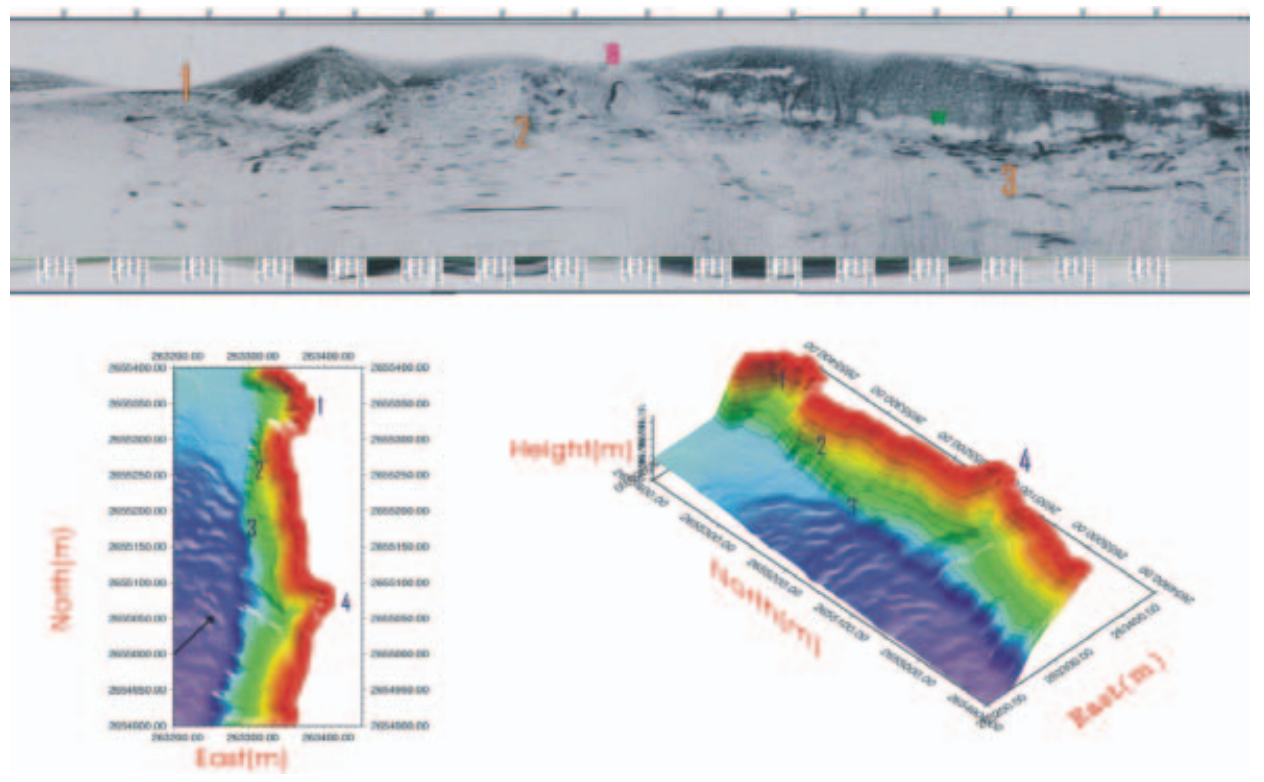

Figure 15. Subaqueous landslide, marked by 'S', shown in the port channel of the side-scan image at location 2 . The lower two diagrams show multibeam underwater topography, with a 3-dimensional plot on the right-hand side. The respective locations are marked on the diagrams.

their support during these experiments at the Wushieh Reservoir. In addition, thanks to the following people from my laboratory for their efforts in collecting the data used in this paper: R. Chen, E. Chen, P.K. Liu, J. Chou, D. Chang and S.C. Wen. My assistant, R. Chen, is especially acknowledged for his help in generating some of the figures.

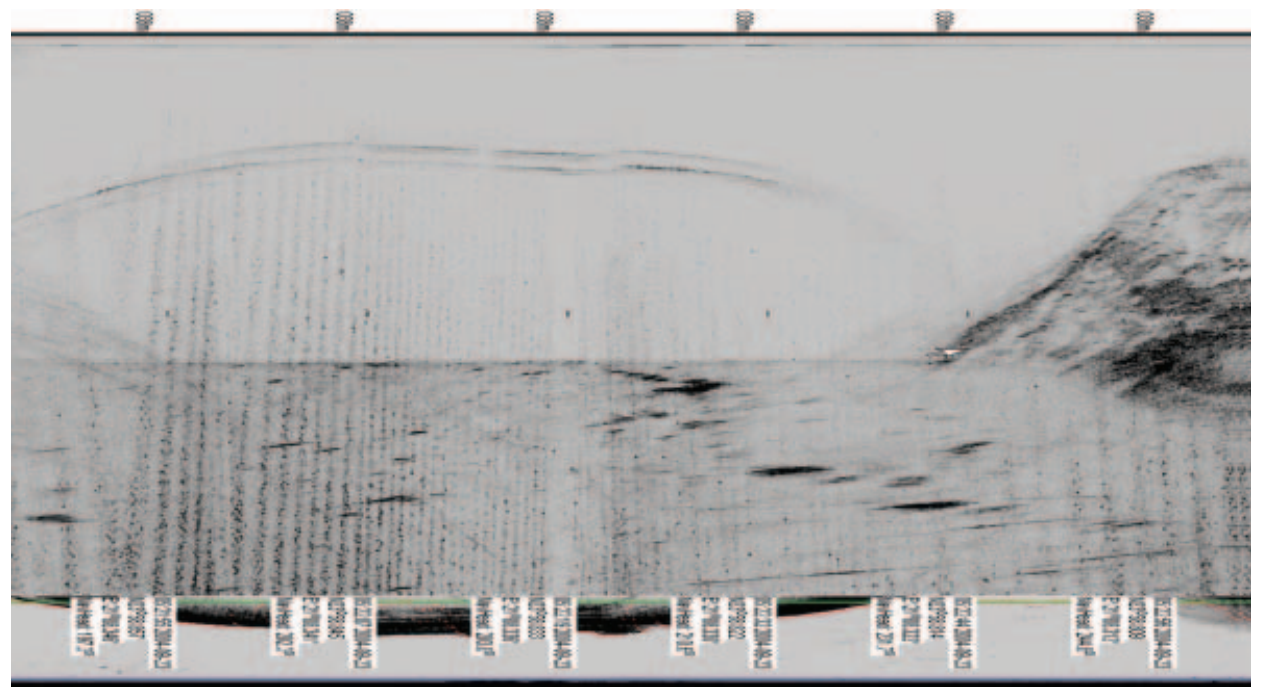

Figure 16. Bottom view of the reservoir in front of the dam in which lots of strong acoustic returns were shown to be fragments of wood lying on the clayey bottom. 


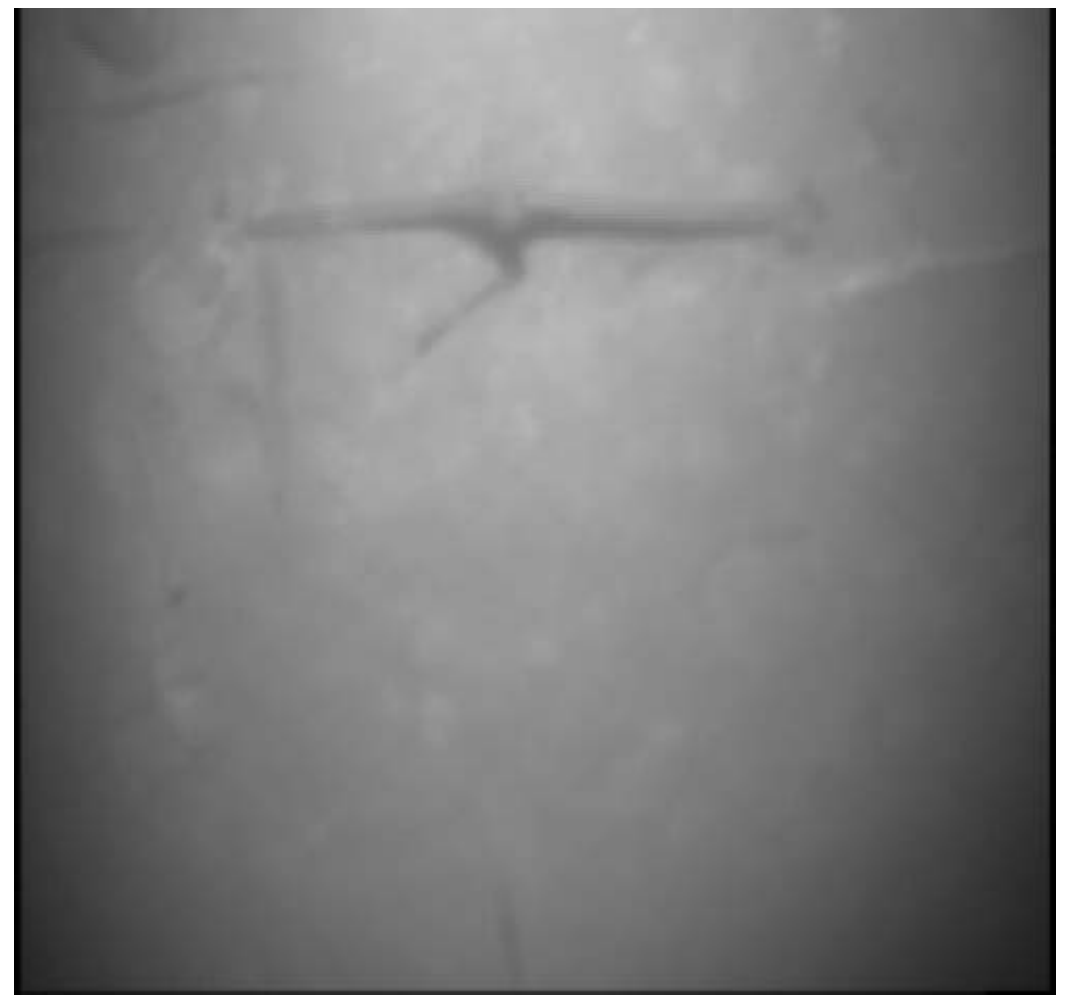

Figure 17. Underwater picture taken from the video showing the bottom view in the front of the water intake of the Wanda Hydroelectric Power Plant, Taiwan.

\section{References}

Duck, R.W., McManus, J. and Lord, J., 1993, Seismicity and bed sediment morphology in a Perthshire Reservoir, UK. In J. McManus and R.W. Duck (Eds). Geomorphology and Sedimentology of Lakes and Reservoirs (Chichester: John Wiley \& Sons).

EdgeTech 1988, Model 272TD Tow Fish Operation Manual (West Wareham, MA: EdgeTech Environmental Equipment).

Fish, J.P. and CARR, H.A., 1990, Sound Underwater Images; a guide to the generation and interpretation of side-scan sonar data (Cataumet, MA: American Underwater Search and Survey).

Flemming, B.W., 1976, Side scan sonar: a practical guide. The International Hydrographic Review, 53, pp. 65-91.

McManus, J. and Duck, R.W., 1983, Sidescan sonar recognition of subaqueous landforms in Loch Earn, Scotland. Nature, 303, pp. 161-162.

Searle, R.C., Le Bas, T.P., Mitchell, N.C., Somers, M.L., Parson, L.M. and PATRIAT, P.H., 1990, GLORIA Image Processing: The state of the art. Marine Geophysical Researches, 12, pp. 21-39.

SonG, G.S., 2002, Measurements of reservoir siltation in the Wushieh and the Mintang Power Plant under sediment yielded from the occurrence of the 921 Earthquake. Taiwan Power Company Final Report, TPC-531-90-2851-11, 145 pp., in Chinese with English abstract.

Song, G.S., 2004, Quantification and mitigated strategy of sedimentation in the reservoir of the Wanda Hydroelectric Power Plant. Taiwan Power Company Final Report, TPC546-91-3304-01, 196 pp., in Chinese. 